\title{
Early-onset X-linked optic atrophy
}

INSERM

\section{Source}

INSERM. (1999). Orphanet: an online rare disease and orphan drug data base. Early-onset X-linked optic atrophy. ORPHA:98890

Early-onset X-linked optic atrophy is a rare form of hereditary optic atrophy, seen in only 4 families to date, with an onset in early childhood, characterized by progressive loss of visual acuity, significant optic nerve pallor and occasionally additional neurological manifestations, with females being unaffected. 